\title{
Eros cindido: representação nos outdoors de São Paulo antes da lei "Cidade Limpa"
}

\section{Luciana Coutinho Souza}

\section{Resumo}

Este artigo cujo objeto são os outdoors do Minhocão de São Paulo, antes da Lei "Cidade Limpa", tem como objetivo explicitar a natureza dos signos presentes na paisagem urbana de São Paulo representada pelo Minhocão. 0 percurso metodológico se fez a partir da coleta de dados registros fotográficos de outdoors na cidade de São Paulo - e análise semiótica das referidas peças, fundamentando-se na semiótica de Charles Sanders Peirce, nas ideias de Ferrara acerca da cidade como sistema de signos, nos estudos sobre palavra e da imagem desenvolvidos por Nöth e Santaella, bem como em ideias de Bataille sobre o erótico que se constitui como temática dos outdoors.

Palavras-chave

Publicidade de rua. Palavra/imagem. Erotismo.

\section{Luciana Coutinho Souza | luciana.souza@prof.uniso.br}

Doutora em Comunicação e Semiótica pela Pontifícia Universidade Católica de São Paulo - PUCSP. Professora do Mestrado em Comunicação e Cultura da Universidade de Sorocaba - UNISO.

\section{Introdução}

Este artigo é resultado da primeira das três fases da pesquisa intitulada "A relação palavra/imagem na mídia outdoor: um estudo comparativo entre São Paulo e Berlim" que, por sua vez, dá continuidade ao projeto "Estudo intercultural, Alemanha e Brasil, das relações entre palavra e imagem nas mídias", sob a coordenação de Lucia Santaella (lado brasileiro) e Winfried Nöth (lado alemão) ${ }^{1}$.

A cidade de São Paulo, antes da lei "Cidade Limpa"2, escondida atrás de uma desordenada invasão de signos - outdoors, faixas, fiações, luminosos, banners -, geradora do caos, é a paisagem poluída que atua como cenário das reflexões que ora daremos vazão neste artigo. Da miríade de signos de que se constituía sua paisagem urbana, recortamos os outdoors e os elegemos como objeto, mais especificamente, os outdoors presentes no Minhocão (Elevado Costa e Silva) - outro recorte que, a nosso ver, funciona aqui como microcosmo da cidade de São Paulo.

Outros olhares já resgataram a paisagem urbana sob pontos de vista variados. Uma leitura de 
cidades que teve São Paulo como protagonista foi feita por Brissac em Paisagens urbanas (1996), cujo foco encontra-se na arte e sua relação com o espaço urbano. 0 autor vê a cidade como linguagem, onde tudo se presta de imediato à descrição, ao mapeamento. 0 que dela se apreende são figuras de coisas que significam outras coisas... signos, portanto. Como a cidade é carregada pelo invólucro de símbolos, parece impossível saber o que contém e o que esconde (p. 26). É por meio de índices que se constrói um quadro de lugares: os monumentos funcionam como mapas, traçam o perfil da cidade; são marcos que estabelecem a história e os caminhos do lugar, que reduzem suas espessas camadas de vida a signos exteriores erguidos sobre a grama (p. 29). 0 que Brissac propõe é reinventar a localização e a permanência por meio da arte, construir imagens da cidade que sejam novas, que passem a fazer parte da própria paisagem urbana e, através dessas paisagens, redescobrir a cidade.

\section{Em Espaços comunicantes, a dimensão}

comunicativa do conceito de espaço que constrói signos não verbais, nos mais variados suportes, traduz o enfoque de Ferrara (2007), cujas obras Ver a cidade (1988) e Estratégias dos signos (1978) são também aqui retomadas. Trata-se de um exercício de leituras que busca observar o modo como se organizam as espacialidades. Mas é o recorte da espacialidade que vai da cidade como função e uso ao ambiente que se comunica como espaço social que recai nosso foco de interesse. Em Drigo e Souza (2008) - A paisagem urbana como sistema de comunicação: um olhar para a cidade de São Paulo - a cidade de São Paulo foi também revisitada sob o ponto de vista da paisagem urbana como meio de comunicação. Nessa visada, num contexto pós-lei "Cidade Limpa", buscou-se anunciar possibilidades de distribuição da publicidade de rua em consonância com o contexto urbano. Essas produções nos posicionam sobre 0 estado da questão nos estudos sobre a cidade como linguagem. Para caracterizar o foco deste artigo, voltemos, agora, nosso olhar para a descrição dos recortes do objeto, do contexto antes da lei "Cidade Limpa", do percurso metodológico, bem como do trajeto que delineia nossa investigação.

De maneira panorâmica, esta primeira fase, que se faz objeto deste artigo, consistiu na leitura da publicidade altamente poluidora da São Paulo antes da lei "Cidade Limpa", a partir de 300 fotografias feitas da cidade, às vésperas da adoção da lei. Nas duas outras fases da pesquisa, empreendemos, inicialmente, uma análise comparativa da cidade de São Paulo com Berlim, tendo em vista aspectos referentes à natureza dos signos presentes, à relação palavra e imagem e em busca de temáticas que fossem confluentes. Finalmente, numa terceira etapa, buscaremos sugerir formas de tratamento das relações entre palavra e imagem que transcendam aspectos culturais específicos desses contextos e permitam um diálogo intertextual harmônico com a paisagem da cidade que thes serve de suporte.

Lei aprovada pela Câmara de Deputados e publicada a 26 de setembro de 2006 que, na busca de combater a poluição visual, proibiu a exibição de todo material publicitário. Ela intenta, entre outros propósitos: a) recuperar a memória cultural de São Paulo; b) propiciar o bem-estar estético, cultural e ambiental da população; c) possibilitar a percepção e a compreensão dos elementos referenciais da paisagem; d) assegurar a preservação e a visualização das características peculiares dos logradouros e das fachadas bem como a dos elementos naturais tomados em seu conjunto e em suas peculiaridades ambientais nativas; e) 0 equilíbrio de interesses dos diversos agentes atuantes na cidade para a promoção da melhoria da paisagem do município. 
Nossa leitura desses elementos urbanos se assenta numa perspectiva semiótica, isto é, tomamos esse tecido urbano como sistema de signos: de um lado, a linguagem híbrida dos outdoors; de outro, a linguagem não-verbal desse fragmento da cidade - 0 elevado - que com os outdoors convive e dialoga. Nesses elementos da morfologia urbana - vistos semioticamente -, 0 signo é lido sob o enfoque de sua materialidade concreta, seu contexto e seu interpretante. "É a determinação da relação desses três elementos, 0 signo, o objeto e 0 interpretante, que transforma a realidade urbana em realidade sígnica e dimensiona sua potencialidade enquanto sistema de comunicação" (FERRARA, 1988, p. 44).

Por essas razões, para que 0 ambiente urbano seja compreendido enquanto sistema de linguagem ou de comunicação, tomamos como primeiro passo metodológico sua análise como signo e, para tal, buscamos na teoria semiótica de Peirce 0 instrumental que lançará luzes nessa empreitada. Ainda nas palavras de Ferrara (idem, p. 44)

Processos de semiotização e leitura constituem, pois, atividades correlatas que se interdependem e se aglutinam muitas vezes porque, se a primeira é transformar signicamente 0 objeto construído, a segunda é a descoberta da natureza desse processo sígnico.

A semiótica faz falar 0 signo e empresta ainda sentido estrutural ao objeto construído, tornando observável a comunicação.

Feita essa justificativa metodológica, segue a descrição do contexto - objeto dos signos em foco - que ampara essa leitura. Mais precisamente, o momento capturado data de meados de dezembro de 2006: a cidade de São Paulo, que se fazia vitrina, encontrava-se na iminência da adoção da nova lei.

Tomando conta das fachadas dos prédios, engolindo o mobiliário urbano, os outdoors - signos invasores como o próprio Minhocão agigantavam-se e ofereciam ao olhar do "leitor movente" uma profusão de imagens e palavras que poluíam visualmente 0 ambiente. Dessa observação, advieram algumas questões relativas à natureza dos signos que se faziam presentes nas peças publicitárias, à maneira como eles dialogavam entre si e com aquele fragmento da cidade. Qual seria a natureza desses signos presentes na paisagem urbana de São Paulo, representada pelo Minhocão? A partir dessa questão chave, outras se delinearam: que relação interna ou intertextual entre palavra e imagem se estabelecia no campo gráfico dessas peças? E afinal, predominaria nesses signos/outdoors alguma temática?

É para essas questões que buscaremos "quase-respostas".

\section{Minhocão e outdoors: sistemas sígnicos em diálogo}

Em meio ao burburinho que antecipava o Natal, uma "sensorialidade alucinógena" convertia a cidade em mercadoria. Povoada de imagens, São Paulo vestia-se de consumo e um desfile de aparências fugidias operava a sedução. 0 leitor 
que se locomovia pela via elevada (figuras 1, $2 \mathrm{e}$

$3)^{3}$, momentaneamente, se via levado a penetrar num outro universo, feito de mar e sol, que a Via Marte prometia; ou fugir do tumulto da cidade em uma possante motocicleta que certamente o levaria a lugares só possíveis em sonho; 0 convite ao sono feito pela Probel se misturava ao convite sensual de beldades que pareciam oferecer-se para compartilhar dos mesmos sonhos, eróticos, é claro. Calcinhas e cuecas sintetizavam o caráter de sensualidade e de efemeridade que 0 curto tempo de contemplação - olhadela - permitia. Da cultura do descartável, do evanescente se imbuía a poluição visual que tomava a cidade: simbologia do fetiche.
$\mathrm{Na}$ correnteza caótica de imagens, o leitor passante convivia com a superexposição perceptiva da velocidade com que imagens atravessam a retina, congestionando-a. Nesse cenário, absolutamente indicial, São Paulo submergia. Lembremos que indicial, na semiótica peirceana, é a natureza dos signos que, na relação com o objeto, caracteriza-se pela emergência do aqui e agora, pelo fisgar de nossos sentidos, pelo aguçar de nossa experiência. 0 tipo de reação que tais signos provocam - interpretantes - é sempre constatação. Não nos leva a contemplar ou a fazer reflexões razoáveis sobre o que vemos, daí excitarem nossa percepção, isto é, inundam nossa mente de perceptos.
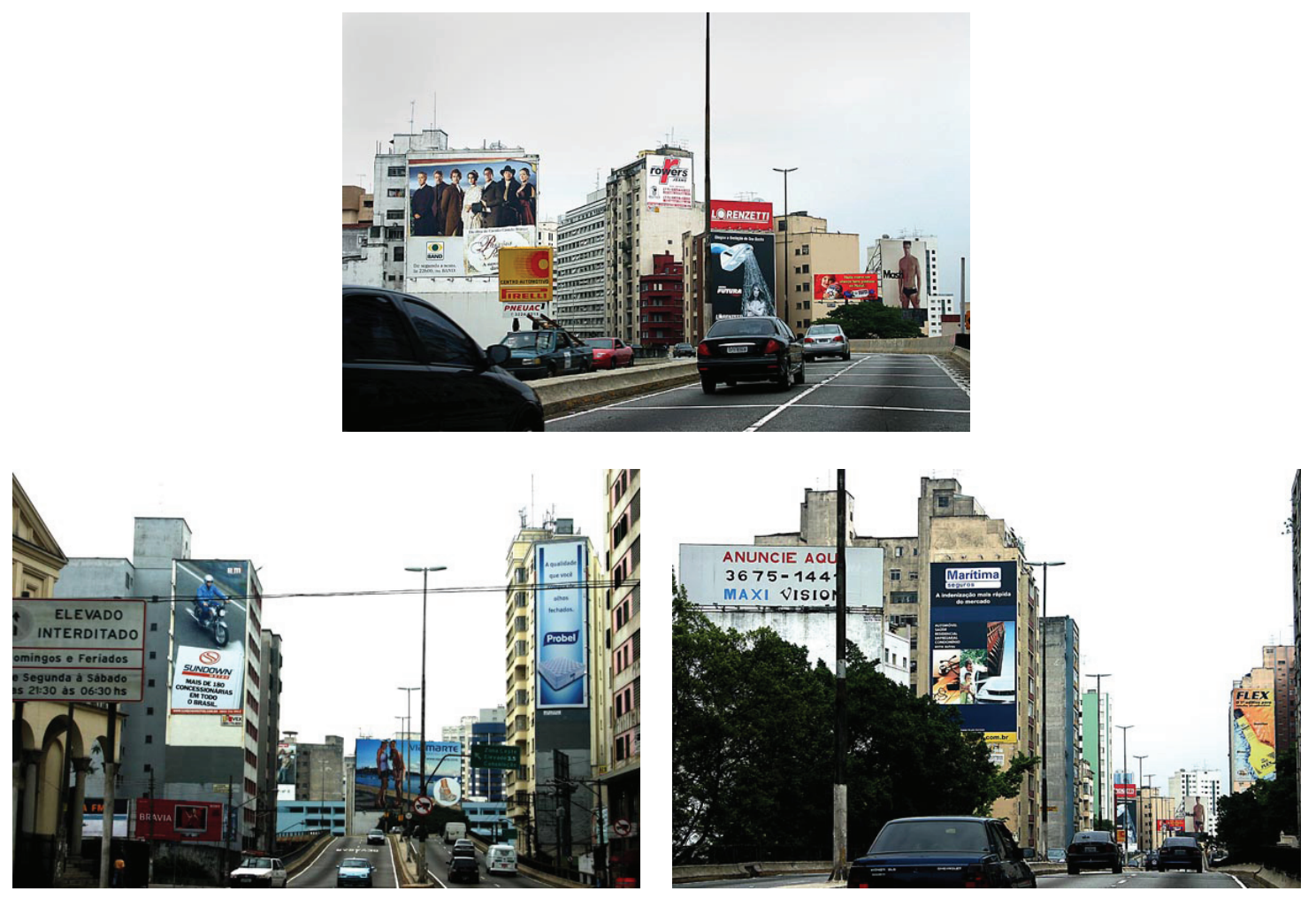
O Elevado Costa e Silva - pedaço da São Paulo poluída, ruidosa, invasora (de nossa percepção) e invadida - já se constitui como elemento poluidor do espaço. Ferrara (1988) propõe dois tipos de poluição em ambientes urbanos. A primeira é a aglomerativa "que ocorre em ambientes onde se registra acúmulo desordenado de elementos que não chegam a constituir um repertório porque não codificam, não obedecem a um princípio de ordem" (idem, p. 46); a segunda é a imprevista: poluição que "ocorre em ambientes onde se registra tentativa de organização de um sistema novo, introduzindo uma variedade nova de usos e significados que correspondem à elevação do repertório a uma taxa superior de informação" (idem, p. 50). Aos olhos da mesma autora, a esta segunda categoria corresponde a poluição espacial do Minhocão.

0 elevado rasga a cidade na sua aridez de concreto, quebrando a continuidade ou a harmonia que se pretendia previsível no espaço urbano. Considerando-o, sobretudo, como signo ou sistema de comunicação, o Minhocão polui porque rompe com a ordem institucionalizada. "É signo que, através de sua organização sintática, apresenta ao interpretante uma reformulação do repertório pela introdução de uma taxa informativa que, pragmaticamente, perturba o conceito de ambiente urbano entendido como objeto do signo" (FERRARA, idem, p. 53).

Era ainda, no momento em que foi capturado, reduto de contrastes, à medida que permitia a convivência do encardido e feio com 0 belo vindo das musas que estampavam as fachadas dos prédios e acompanhavam os movimentos do leitor/passante: modelos famosas tanto pela beleza quanto pela "conduta" impregnavam de sensualidade 0 viaduto (figuras 4,5 e 6 ).
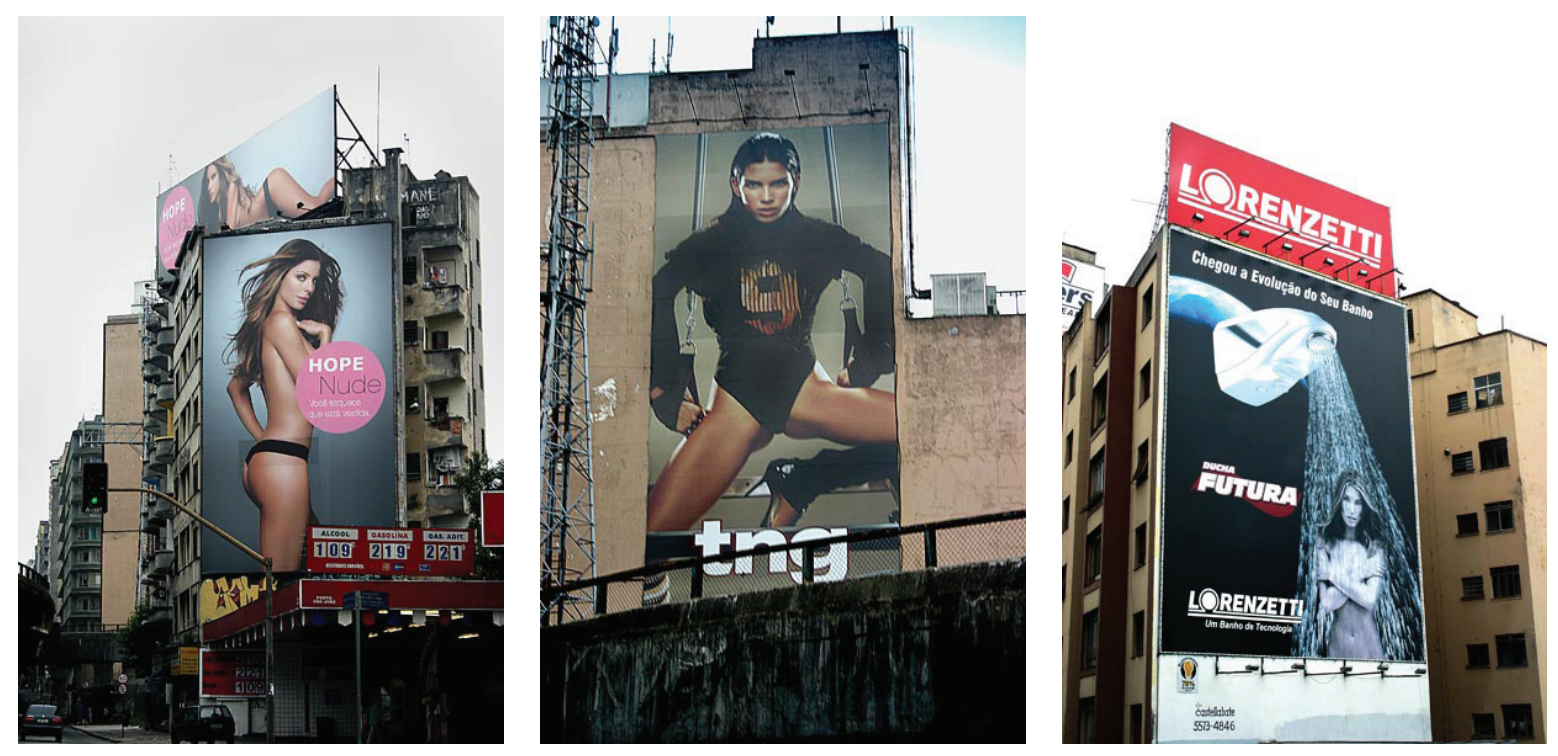
Contudo, outros signos apontam para sentidos que não mais contrastam, mas os aproximam. Nas palavras de Ferrara (1988), o Minhocão oferece ao usuário a organização sígnica do caótico e do vulgar. A vida urbana cotidiana é estendida para fora das janelas, revelando toda uma intimidade: roupas expostas em varais improvisados, lixo à mostra, cozinhas e dormitórios vasculhados. A vulgaridade é, portanto, comum a ambos os sistemas sígnicos: Minhocão e outdoors que o margeiam. Também com relação à sensualidade excessiva das modelos, encontramos correspondência na própria constituição estrutural da via elevada: sua forma é fálica e penetra, por entre prédios, na intimidade ao oferecer ao olhar de voyers as janelas ao seu entorno, é invasivo da privacidade.

Vem daí a hipótese de que a eroticidade é a qualidade predominante dos signos que ali se erguiam. Dois, portanto, são os pontos em que os sistemas de signos em exame se cruzam: primeiro, por serem ambos elementos morfológicos da cidade altamente poluentes; segundo, por terem em comum a natureza do erótico como qualidade do signo e como temática.

Trilhar os caminhos movediços de Eros nos levará a vislumbrar a temática que reveste tanto os outdoors, quanto o mobiliário urbano para o qual se voltam. Voltemos nossos olhos ao erótico.

\section{0 erótico como tema}

Sabemos que cada sociedade constrói uma visão de corpo que representa os seus valores, um corpo em estado de cultura. A questão do erótico, embora se faça tão intensa nos dias atuais, já estava em Platão. Na esteira de Georges Bataille (1988) e de estudiosos do tema, Francisco Camargo e Tânia Holf (2002), Lucia Castello Branco (2004), buscaremos ver o erótico à luz da mitologia e de suas imbricações filosóficas, para depois pensarmos em que faceta de Eros a natureza dos outdoors em questão se encaixa.

0 mito grego nos diz que Eros é o deus do amor. Sua capacidade de unir ou aproximar ultrapassa os limites da união sexual ou amorosa e se estende à ideia de conexão com a origem da vida ou com seu fim - a morte -, com o cosmo, conexões estas que desencadeariam sensações de completude, de unidade. Essa ideia já estava presente em O Banquete de Platão (1972). Conta Aristófanes, convidado do banquete, que antes do nascimento de Eros a humanidade se compunha de três sexos: 0 masculino, 0 feminino e 0 andrógino. Esses últimos seres eram redondos, tinham apenas uma cabeça, mas duas faces, duas genitálias e quatro eram os braços, as pernas, as orelhas. Essa natureza os tornava imbuídos de tal poder que decidiram desafiar os deuses. Zeus então os castiga: corta-os ao meio, tornando-os mais numerosos para melhor servirem aqueles a quem desafiaram. Mutilados e incompletos, esses seres partiram em busca da sua metade que, quando resgatada, resultava num infinito desejo de união. Foi daí que se originou Eros, o impulso para "recompor a antiga natureza" e "restaurar a antiga perfeição". 
Esse desejo de ser um com os objetos do mundo é 0 impulso do erótico descrito por Freud e desenvolvido por Georges Bataille em O erotismo (1988). 0 conceito de erotismo é entendido por Bataille como impulso resultante de duas forças antagônicas, mas complementares: vida e morte.

Há ainda outra versão para a complexidade da natureza de Eros que acentua esse caráter de união dos opostos. Filho de duas divindades, Póros (Expediente) e Penía (Pobreza), herdou de cada um deles, respectivamente, a capacidade de arquitetar ou planejar e a carência ou "falta de". Amar 0 erótico é, em suma, planejar 0 tempo para resolver uma carência. Estar a meio caminho entre a carência e a possibilidade de realização plena implica em integrar, numa única manifestação, antagonismos. Vida e morte, por exemplo. Eros é o desejo de vencer a própria morte que se traduz na procriação, na continuidade da existência, na manutenção da espécie. E, aqui, retorna a noção freudiana da pulsão de vida que se opõe à pulsão de morte.

Assim entendido, o erótico não se restringe à função genital - sexo -, mas vai além, refere-se a todo tipo de excitação e de atividades que mantêm e alimentam nossa vontade de viver - sexualidade.

Camargo e Holf atam a pontas do erótico,

0 domínio do erótico estende-se desde o corpo, instância em que se manifesta 0 sexual, até a consciência, instância de representação e realização sígnica. A ação concomitante dessas duas instâncias explica porque o corpo serve de palco para a sua realização, mas também, ao mesmo tempo, a consciência 0 apreende para pensá-lo e traduzi-lo em linguagem - 0 que lhe permite extrapolar os limites do ato sexual para registrálo e circunscrevê-lo num ritual. Nesses termos, 0 erótico compreende o que é carnal - 0 sexo - e 0 que é sublime - 0 amor (2002, p. 35).

Imbuídos da ideia de continuidade, o sexo (preservação da vida) e a consciência (preservação através da permanência de ideias ou das utopias da vida eterna) expressam-se no erotismo. Também se expressa no erotismo 0 amor à sabedoria. Este último, ao mesmo tempo em que se contrapõe, realiza-se no desejo de gozo: manifestação plena da natureza unificadora do erótico: "quanto mais se eleva na direção do saber, que é 0 aprimoramento da alma, mais se aproxima do corpo e de suas realidades de realização - o gozo" (CAMARGO; HOLF, 2002, p. 37).

A versão moderna do erótico traz uma cisão entre o filosofar e o gozar. Nas palavras de Camargo e Holf (2002), o erótico cindido tende ao aspecto do gozo (carnal) em detrimento do filosófico (intelectual).

$\mathrm{Na}$ modernidade, 0 erótico deixa de ser um saber filosófico, para servir a uma necessidade econômica. Há uma educação erótica que ensina 0 que deve ser filosófico e, separadamente, disciplina o gozo. 0 nosso envolvimento na sociedade, nossa forma de produzir e existir economicamente define o quanto de saber, ou consciência, e o quanto de disciplina de gozo devemos ter (p. 38-39).

Lembremos aqui que nossa abordagem recai na linguagem, desde 0 tratamento dado à cidade 
quanto aos outdoors; logo, o erótico aqui também se constitui como tal. 0 erótico circunscrevese no meio social, é uma combinação de signos imbuídos de uma convenção e realiza-se como expressão de elementos que se combinam no corpo e representam modos de pensar sobre ele e de significá-lo.

0 sexo é ação do corpo e o remete ao estado de natureza; já o erótico é representação do corpo e 0 insere na cultura, por isso é discurso, cuja finalidade é comunicar ao outro uma vontade de continuidade que será compreendida graças aos códigos de comportamento social (idem, p. 42).

Quando o sexo deixa de se realizar na relação sujeito-sujeito e passa a realizar-se numa relação de coisificação (sujeito-objeto, objeto-objeto), então estamos diante da pornografia. Ainda que seja difícil a delimitação dessas fronteiras, passemos ao pornográfico.

Uma das distinções que se fazem entre os dois fenômenos recai na leitura da oposição entre o que é nobre e grandioso e o que é vulgar e grosseiro. Tais atributos revelam o caráter moralizante que se esconde nessa concepção: nobre porque "veste" a sexualidade; grosseira porque exibe o sexo "nu", é explicita. Tentando não nos fixarmos no uso comum, recorremos a Castello Branco (2004).

Com o surgimento da indústria cultural [...] passam a ser consideradas eróticas as chamadas obras de arte que abordem temas vinculados direta ou indiretamente à sexualidade, enquanto são relegadas ao segundo plano, 0 da pornografia, as obras sobre sexo, produzidas geralmente em série, e com objetivo prioritário de comercialização e consumo (p. 21).

A própria etimologia da palavra pornografia ${ }^{4}-$ do grego pornos (prostituta) e grafos (escrever)

- que já traz embutido o aspecto comercial, consumista, corrobora a marca que o fenômeno da industrialização imprimiu ao material pornográfico.

Fazendo alusão ao mito platônico, enquanto 0 erotismo caminha em direção à unificação dos seres mutilados, a pornografia insiste na mutilação dos seres, no gozo parcial, individual e solitário. Contextualizado em nossos dias, é 0 aspecto comercial que intensifica essa cisão. As palavras de Camargo e Holf balizam essa concepção.

Atualmente, o erotismo encontra-se muito próximo da pornografia. Desprovido da dimensão intelectual e marcado pelo código econômico, quase não se distingue do pornográfico. Está presente em todas as formas discursivas, sempre numa dimensão econômica, e não mais como erótico propriamente dito (idem, p. 46).

$\mathrm{Na}$ esteira desses autores e das ideias apresentadas até aqui, chegamos à representação do corpo criado pelas relações erotismo/ pornografia/economia que vimos deslindando. Chegamos ao "corpo-mercadoria" ou "corpomídia", atual representação do feminino que nos permitirá ver/ler as imagens dos outdoors que margeavam o Minhocão. Em que faceta de Eros se inscrevem esses signos? 


\section{0 corpo-mídia em evidência: uma leitura semiótica}

Na apreensão do potencial de significação dos

signos/outdoors, buscaremos nos deter nas três instâncias do erótico, aquelas que se referem às três maneiras de se apreender o real sob a ótica da Teoria dos Signos de Charles Sanders Peirce (1931-1966). Não por acaso o número três é recorrente nessa leitura, afinal, toda arquitetura filosófica de Peirce está estruturada nas suas categorias fenomenológicas ${ }^{5}$ : primeiridade, secundidade e terceiridade.

A primeira instância capta 0 erótico na sua manifestação mais sugestiva e fugaz. Ele é apreendido pelos sentidos, via qualidades da cor, das formas, da dimensão, da textura, da posição que ocupa na composição visual, de detalhes que se delineiam, enfim, das qualidades materiais dos signos. A segunda - ao explorar 0 campo referencial dos signos, a maneira como apontam para o contexto imaginário ou fatual a que se referem - capta 0 erótico como um existente que se materializa e evoca, apela, insiste. A terceira instância diz respeito ao nível de interpretabilidade dos signos ou sua capacidade de generalização. São os códigos de convenção do erótico que vêm à baila. Cada uma dessas instâncias, segundo Santaella (2002), caracteriza um tipo de olhar: 0 contemplativo, 0 observacional e, por fim, o generalizante.

0 contexto ou referente de cada publicidade a ser analisada sob o tema do erótico tem como objeto dinâmico - fora do signo - o produto anunciado. 0 modo como cada um dos produtos é representado nos outdoors - o objeto imediato do signo será nosso material de leitura. As estratégias de produção de sentido empregadas nessas representações equivalem aos interpretantes que buscaremos dar vazão nessa análise.

Seguindo o percurso do olhar anunciado, retomaremos as três imagens já mostradas (figuras 4,5,6) e incluiremos outras, também representativas. Comecemos pela contemplação... Os olhos lânguidos da modelo da figura 4; as formas ora arredondadas, ora sinuosas; os lábios grossos levemente entreabertos; a leveza dos cabelos esvoaçantes, a posição dos braços em espera, a tira preta que, tal como uma "tarja", esconde o proibido, compõem os elementos que, num primeiro momento, colhemos desse outdoor. Sobre um fundo azul, que impregna 0 campo visual de sensações energéticas, festivas e receptivas, uma forma feminina perfeita se oferece aos passantes, insinua-se. Todos esses dados qualitativos sugerem uma sensualidade

"Todos os elementos da experiência pertencem a três classes como elas podem ser definidas em termos numéricos, são denominadas categorias cenopitagóricas. A saber, a experiência é composta de: $1^{\circ}$ ) experiências monádicas ou simples, em que os elementos são de tal natureza que poderiam ser 0 que são sem inconsistência, ainda que nada mais houvesse na experiência; $2^{\circ}$ ) experiências diádicas ou recorrências, onde cada uma é uma experiência direta de um par de objetos em exposição; $3^{\circ}$ ) experiências triádicas ou compreensões, onde cada uma é uma experiência direta de conexão com outras experiências possíveis" (PEIRCE, 19311966, p. 7.528). 
latente, tão intensa, que fugaz é o tempo de contemplação.

A figura 5, posta no início do viaduto, em tamanho gigantesco, tem um olhar que vai além da pura languidez. É agressivo, quase imperativo. Seu corpo/escultura se mostra geometrizado: braços e pernas formam ângulos, aproximadamente retos, similares aos contornos dos edifícios. A cor preta intensifica a grandiosidade da figura que se assoma. Segundo Arnheim, "a imagem pode ser pensada como um campo de força e a sua visão como um processo ativo de criação de relações, frequentemente instáveis e mutáveis" (apud AUMONT, 2002, p. 150). Nesse caso, cabe ao espectador a determinação do centro das imagens, já que seu interesse se concentra justo na organização diferenciada, que se confronta com o seu próprio centro absoluto. A composição dos elementos representados na imagem define a organização da cena e determina suas atribuições. Assim, o olhar do leitor é levado a pontos específicos que se quer evidenciar, estabelecendose, dessa forma, uma sequência para a leitura. Especificamente na publicidade, a composição é elaborada de modo a chamar o olhar do leitor para pontos-chave. Linhas de força apontam para o que se quer anunciar. Qual seria o trajeto do olhar dos leitores moventes, senão os vértices dos quase triângulos que as formas - braços, pernas delineiam? A posição da peça publicitária, na abertura da via, já anteriormente caracterizada como também erótica em função de seu aspecto fálico e invasivo, sugere a iminência da cópula.
A mulher inscrita na figura 6 oferece sua nudez para o 'refresco' dos olhos dos leitores/moventes. Uma ducha recobre, como a um véu, o corpo nu. Tal é a força da sugestão do etéreo, que 0 corpo da mulher não é sequer tocado pela água: seus cabelos esvoaçantes são 0 sinal. Suas mãos cruzadas sobre o peito o protegem dos olhos invasores. Virgem e deusa. Uma deusa que, ao contrário da simbólica Vênus de Boticelli a qual emerge das águas, recebe-as como dádiva. Sugestão de purificação...

Duas novas figuras vêm juntar-se às anteriores nesta análise (figuras 7 e 8):

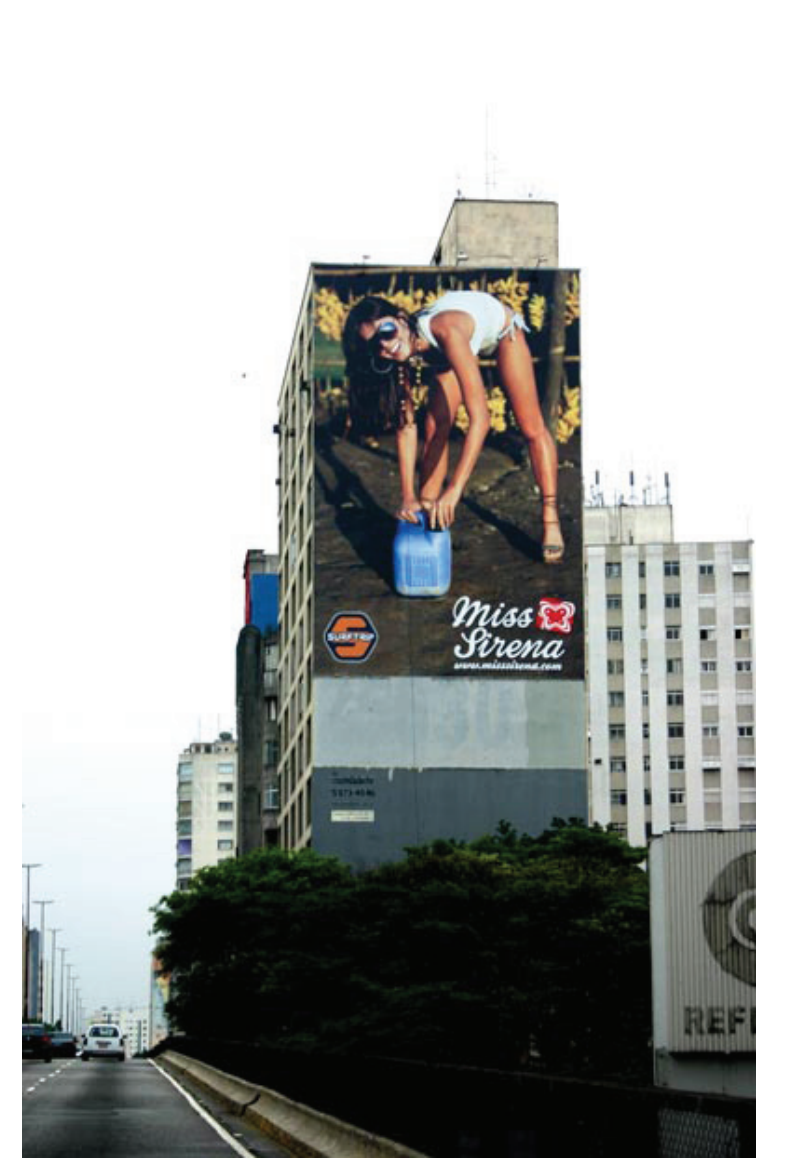

A figura 7 traz não mais a exuberância de uma mulher, mas uma menina. Um ar de brincadeira dá 
o tom dessa imagem, só quebrado pelas sandálias altas que contrastam não só com 0 ar pueril, mas com os trajes que a modelo exibe: camiseta e calcinha de biquíni. Sua ocupação do campo gráfico traz certo desconforto pelo desequilíbrio aparente: a cabeça pendente para a esquerda só é compensada com a presença do slogan à direita. A iminência de uma queda pode ser provocadora do riso.

Finalmente, a presença masculina desponta (figura 8) nesse universo impregnado pelo feminino. Mais distante do campo visual que os outdoors anteriores, um homem de cueca posa para ser visto numa curva do elevado. Corpo malhado, olhar penetrante, preto no branco: pura e simples sugestão. Nada ali exagera: vemos tão-só alguém que simplesmente se oferece à leitura. Para Arnheim (1969 apud AUMONT, 2002), o equilíbrio é a meta final de qualquer desejo a ser realizado, de qualquer trabalho a ser completado. Trata-se de uma necessidade natural da nossa percepção visual. Na composição equilibrada, todas as tensões dirigidas, todas as forças de atração e repulsão, compensam-se mutuamente e a totalização do padrão aponta a pausa. 0 equilíbrio visual, apesar de resultar em estabilidade, carrega consigo toda energia presente nas relações entre seus elementos. E 0 corpo masculino se impõe em pleno equilíbrio, ao seu redor, instaura-se 0 silêncio...

A configuração do erótico nessa instância contemplativa se dá pela languidez, agressividade ou profundeza no olhar; pelas formas capturadas no que a nudez permite entrever, ou naquilo que as vestes permitem prever; bocas entreabertas, sedutoras, fartas de promessas. Por isso, o apelo de todas essas imagens, à margem do Minhocão, instaura a segunda instância: a secundidade peirceana que se faz predominante. Põe-se em ata 0 olhar observacional.

Lembremos que a linguagem visual está dominantemente enraizada na secundidade. Nos outdoors, essa categoria é acentuada a partir da sua própria gênese sígnica. A fotografia é neles matéria- 
prima. 0 grau de indexicalidade da fotografia com referência a Peirce já foi bastante discutida por Dubois (1993), Schaeffer (1987), Santaella e Nöth (1997); também a indexicalidade presentifica-se na análise de outros semioticistas como Barthes (1980). A condição de índice da imagem fotográfica implica que a relação que os signos indiciais mantêm com seu objeto referencial seja sempre marcada por um princípio de conexão física, de singularidade. Retomaremos aqui algumas ideias.

Dubois (1993) trata o aspecto indicial da fotografia, denominando-a como traço do real. A imagem indicial é dotada de um valor singular, determinado unicamente por seu referente e só por esse traço de um real. Para Schaeffer (1987, p. 101), o signo fotográfico é, "ao mesmo tempo, um índice icônico e um ícone indicial".

Para Santaella e Nöth (1998), a imagem da foto torna-se inseparável de sua experiência referencial, do ato que a funda. Sua realidade primordial nada diz além de informar sua existência. É a lógica do índice que confere à imagem essa força incessantemente sentida com violência. A foto é, em primeiro lugar, um índice. Só depois ela pode tornar-se parecida (ícone) e adquirir sentido (símbolo).

Na esteira desse impacto do referente sobre a imagem fotográfica, estão as ideias de Barthes (1981). Sua famosa definição ontológica está no "isso foi" e nada pode ser mais representativo da indexicalidade que essa marca deixada pelo referente no signo. Também quando Barthes refere-se à "extensão metonímica do punctum" evidencia na fotografia a força do índice ao fisgar o olhar do outro.

0 predomínio de signos indiciais - representados aqui pelos outdoors -, num determinado local, leva-nos a transitar por traços, marcas, pegadas, pedaços. Forçam-nos a olhar um e outro sem reter por muito tempo nossa visão. A reação que provocam é de mera constatação "isto é", nossa consciência se vê atordoada pela chuva de perceptos que se desencadeia. Este é o universo da secundidade.

Voltando à análise dos outdoors, agora sob o domínio do olhar observacional, fisgamos imagens de corpos (ou somos fisgados por elas...) que oferecem mercadorias e também se oferecem como tal. Peças íntimas femininas e masculinas, duchas, roupas são anunciadas e tornadas fetiches na tessitura dos corpos em exposição. As figuras agigantam-se, apelam, chamam, seduzem. Esse embate é altamente indicial e remete-nos a um mundo do consumo impregnado pelo desejo. Este é o referente. 0 erótico nessa instância, age, seduz, fisga. Materializa-se nos movimentos, gestos, atitudes, vestimentas, adornos, rituais, ocasiões.

Seguindo sugestões e pistas, chegamos à instância da terceiridade, do signo simbólico $0^{6}$.

"É por força de uma ideia na mente do usuário que o símbolo se relaciona com seu objeto. Ele não está ligado àquilo que representa através de alguma similaridade (caso do ícone), nem por conexão causal, fatual, física, concreta (caso do índice). A relação entre o símbolo e seu objeto se dá através de uma mediação, normalmente uma associação de ideias que opera de modo a fazer com que 0 símbolo seja interpretado como se referindo àquele objeto. Essa associação de ideias é um hábito ou lei adquirida que fará com que o símbolo seja tomado como representativo de algo diferente dele." (SANTAELLA; NÖTH, 1998, p.63) 
Aqui, o olhar ultrapassa o que vê e avança pelas generalizações. Assim, para além dos corpos que se expõem, está a configuração do erótico modelar. 0 corpo perfeito - saudável, esbelto, malhado - corresponde a um estilo de vida e deve ser tomado como ideal não no que se refere à essência, mas à aparência. Corpo de natureza sígnica, corpo/texto.0 erótico se realiza nesse corpo ideal e, ainda que não seja apenas sexo, é tão-só a ele que se refere.

Sobre a erotização do produto, Baudrillard (1989), ao tratar a publicidade, ressalta o fato de ser o corpo uma mercadoria como qualquer outra. Diz 0 autor que:

[...] o produto se dá à vista, à manipulação: ele se erotiza - não somente pela utilização explícita de temas sexuais, mas pelo fato de que a compra, a apropriação pura e simples é no caso transformada numa manobra, num roteiro, em dança complexa, acrescentando ao procedimento prático todos os elementos do jogo amoroso: avanço, concorrência, obscenidade, namoro e prostituição (até mesmo a ironia) (BAUDRILLARD, 1989, p. 181).

E o mito de Eros é cindido no nível do simbólico, a sexualidade reduz-se a fragmentos do corpo, a produto que se oferece, à permissividade, é essa a faceta do erótico que sobrevive. Sob nova roupagem, a mercadoria erótica, segundo Camargo e Holf (2002), traz em si aspectos de Penía ("falta") e Póros ("possibilidade de"). Estando o corpo desprovido da complexidade e da simultaneidade próprias da essência do erotismo, os corpos revelados tornam-se objetos de consumo. Dessa forma, articulando a origem do mito a esse corpo moderno, temos que ele

$$
\begin{aligned}
& \text { [...] ora revela ao consumidor a "falta de" - } \\
& \text { descobrimos naquele corpo o que desejamos } \\
& \text { e não possuímos -, ora revela a "possibilida- } \\
& \text { de de" - ainda que tal corpo não se preste a } \\
& \text { realizar nossas intenções, somos possuidores } \\
& \text { de um desejo que pode ser satisfeito (CA- } \\
& \text { MARGO; HOLF, 2002, p. 88). }
\end{aligned}
$$

E a palavra - símbolo por excelência, portanto cabível nessa terceira instância da análise - onde entra na produção de sentidos dessa teia desenredada até aqui? Lembremos que, enquanto signo híbrido, o outdoor é suporte e espaço de convivência da imagem e da palavra. Nas cinco peças analisadas, o papel reservado a esta última no campo gráfico é muito pequeno. São as marcas que dão nome ao referente ou o rotulam, algumas acompanhadas de pequeno slogan.

\section{Na figura 4, "Hope Nude - você esquece que} está vestida", a palavra redobra a carga de sedução já visível na imagem. Esquecer-se de que usa a calcinha Hope Nude significa dar a ela a conotação de uma segunda pele, imperceptível, mas certamente visível aos olhos de outros. A relação que aqui se estabelece é a de complementaridade ${ }^{7}$, isto é, o código verbal acrescenta à imagem uma informação que a 
individualiza: a de que aquela peça íntima tem uma qualidade que as outras não têm.

Já nas outras peças, é a marca que nomeia ou dá identidade ao referente - tng, Lorenzetti, Miss Sirena, Mash. Enquanto marcas, traços, pegadas do objeto a que se referem, são predominantemente indiciais. Contudo, ao incorporarem a gama de sensualidade inscrita na imagem via códigos da sedução, elas se investem da simbologia do erótico e o reforçam. Funcionam como âncoras da imagem, daí a relação palavra e imagem estar inscrita na ancoragem $^{8}$.

Enfim, a palavra, tanto quanto a imagem, concorre para tecer a cisão de Eros. 0 erótico enquanto produto tecido na confluência verbal/ visual é expresso como imagem das relações aparentes: são os corpos na urgência da continuidade física que se mostram.

\section{Considerações finais}

0 contexto da cidade de São Paulo antes da lei "Cidade Limpa" foi cenário de nossas reflexões. Interessava-nos empreender um estudo dos outdoors do Minhocão - Elevado Costa e Silva - naquilo que sua linguagem híbrida (palavra/ imagem) poderia nos apontar. Daí a leitura fundamentada pelo viés da semiótica, com 0 intuito de ler/ver modos de constituição desses signos: sua natureza, os seus modos de intersemiose e a temática que daí poderia advir. Da mesma forma, interessava-nos verificar se as peças publicitárias dialogavam com 0 "fragmento" da paisagem que tinham como suporte.

0 resultado que se revelou aponta para a confluência da temática das peças publicitárias e do próprio Minhocão: 0 erótico uniu as duas pontas.

Contudo, o erótico que se descortina desse cenário é aquele que mais próximo está da pornografia. Eros revela-se mutilado na sua capacidade de ultrapassar os limites da união sexual e de se conectar com o cosmo. Tal como os seres andróginos descritos por Aristófanes, verifica-se nos corpos-mídia, mais uma vez, a fragmentação daquilo que se pretendia completo.

\section{Referências Bibliográficas}

AUMONT, Jacques. A imagem. Campinas, São Paulo: Papirus, 2002.

BARTHES, Roland. A câmera clara. Lisboa: edições $70,1981$.

BATAILLE, Georges. 0 erotismo. Lisboa: Antígona Edições, 1988.

BAUDRILLARD, Jean. 0 sistema dos objetos. 2.ed. São Paulo: Perspectiva, 1989.

BRISSAC, Nelson. Paisagens urbanas. São Paulo: Senac. 1996.

Barthes entende, por ancoragem, uma forma de relação indexical entre texto e imagem. 0 texto possui uma função seletiva, pela qual ele dirige a atenção do observador em direção a determinados elementos da imagem. Ele dirige a interpretação da imagem. os meios linguísticos da relação com a imagem são os dêiticos ('vemos aqui...', ou 'esse porão era sua prisão'). Exemplos de meios não linguísticos de indicação a elementos imagéticos são flechas ou a contiguidade entre escrita e o elemento da imagem. Essa contiguidade, geralmente, possui uma função de denominação ou de etiquetação [...]: a palavra designa a coisa ou a pessoa representada na imagem, como no caso do nome sob uma fotografia. (NÖTH, idem) 
CAMARGO, Francisco C.; HOLF, Tânia Márcia C.

Erotismo e mídia. São Paulo: Expressão e arte, 2002.

CASTELLO bRANCO, Lucia. 0 que é erotismo. São

Paulo: Brasiliense, 2004.

DRIG0, Maria Ogécia; SOUZA, Luciana Coutinho

Pagliarini de. A paisagem urbana como sistema de comunicação: um olhar para a cidade de São Paulo. PóS - Revista do Programa de Pós- Graduação em Arquitetura e Urbanismo da FAUUSP, São Paulo, n.23, jun. 2008.

DUBOIS, Philippe. 0 ato fotográfico e outros ensaios. Campinas: Papirus, 1993.

FERRARA, Lucrécia D'Aléssio. A estratégia dos signos. São Paulo: Perspectiva, 1978.

Ver a cidade. São Paulo: Nobel, 1988.

(org.). Espaços comunicantes. São Paulo: Annablume, 2007.

NÖTH, Winfried. Manual de Semiótica. Sao Paulo: Edusp, 2001. (no prelo)

PEIRCE, Charles Sanders. Collected Papers.

Organização: C. Hartshorne, P. Weiss e A. W. Burks. Cambridge: M, Harvard University Press, 1931-1966. (oito volumes)

PLATÃo. Diálogos. 0 Banquete; Fedon; Sofista; Político. São Paulo: Abril Cultural, 1972.

SANTAELLA, Lucia. Por que as comunicações e as artes estão convergindo. São Paulo: Paulus, 2005.

Semiótica Aplicada São Paulo: Pioneira Thomson Learning, 2002. Lucia; Nöth, Winfried. Imagem: cognição, semiótica, mídia. São Paulo: Iluminuras, 1998.

SHAEFFER, Jean-Marie. Limage précaire. Paris : Seuil, 1987. 


\begin{tabular}{|c|c|}
\hline $\begin{array}{l}\text { Divided Eros: representation } \\
\text { on billboards in São Paulo } \\
\text { before the law "Clean City" }\end{array}$ & $\begin{array}{l}\text { Eros partido: representación } \\
\text { en las vallas de São Paulo } \\
\text { antes de la ley "Ciudad Limpia" }\end{array}$ \\
\hline $\begin{array}{l}\text { Abstract } \\
\text { This article deals with billboards located at the } \\
\text { Minhocão, in the city of São Paulo, before the law } \\
\text { "Clean City", and its goal is to exam the kinds of signs } \\
\text { present in the urban scene in São Paulo, which are } \\
\text { represented by the Minhocão. The methodological } \\
\text { strategy was based on the photographs of billboards } \\
\text { and semiotic analyses of those, supported by Charles } \\
\text { Sanders's semiotic, Ferrara's ideas about the city as a } \\
\text { sign system, the word studies developed by Nöth and } \\
\text { Santaella as well as the ideas presented by Bataille } \\
\text { about the erotic. } \\
\text { Keywords } \\
\text { Street advertising. Image and word. Erotic. }\end{array}$ & $\begin{array}{l}\text { Resumen } \\
\text { Este artículo cuyos objetos son las vallas } \\
\text { del "Minhocão" de São Paulo, antes de la } \\
\text { ley "Ciudad Limpia", tiene como objetivos } \\
\text { explicitar la naturaleza de los signos presentes } \\
\text { en el paisaje urbano de São Paulo representado } \\
\text { aquí por el "Minhocão". El recorrido/ } \\
\text { procedimiento metodológico ha sido desde el } \\
\text { recogimiento de los datos- registros fotográficos } \\
\text { de vallas en la ciudad de São Paulo - y análisis } \\
\text { semiótica de los mismos, fundamentándose en la } \\
\text { semiótica de Charles Sanders Peirce, en las ideas } \\
\text { de Ferrara sobre la ciudad como sistema de signos, } \\
\text { en los estudios sobre la palabra y de la imagen } \\
\text { desarrollados por Nöth y Santaella, así como en } \\
\text { ideas de Bataille sobre la temática de lo erótico. } \\
\text { Palabras clave } \\
\text { Publicidad de calle. Palabra/imagen. Erotismo. }\end{array}$ \\
\hline
\end{tabular}




\section{Expediente}

A revista E-Compós é a publicação científica em formato eletrônico da Associação Nacional dos Programas de Pós-Graduação em Comunicação (Compós). Lançada em 2004, tem como principal finalidade difundir a produção acadêmica de pesquisadores da área de Comunicação, inseridos em instituições do Brasil e do exterior.
E-COMPÓS I www.e-compos.org.br I E-ISSN 1808-2599

Revista da Associação Nacional dos Programas de Pós-Graduação em Comunicação. Brasília, v.12, n.1, jan./abr. 2009.

A identificação das edições, a partir de 2008 passa a ser volume anual com três números.

\section{CONSELHO EDITORIAL}

\section{Afonso Albuquerque}

Universidade Federal Fluminense, Brasil

Alberto Carlos Augusto Klein

Universidade Estadual de Londrina, Brasi

Alex Fernando Teixeira Primo

Universidade Federal do Rio Grande do Sul, Brasil

\section{Alfredo Vizeu}

Universidade Federal de Pernambuco, Brasil

Ana Carolina Damboriarena Escosteguy

Pontifícia Universidade Católica do Rio Grande do Sul, Bras

Ana Silvia Lopes Davi Médola

Universidade Estadual Paulista, Brasil

André Luiz Martins Lemos

Universidade Federal da Bahia, Brasil

Ângela Freire Prysthon

Universidade Federal de Pernambuco, Brasil

Antônio Fausto Neto

Universidade do Vale do Rio dos Sinos, Brasil

Antonio Carlos Hohlfeldt

Pontifícia Universidade Católica do Rio Grande do Sul, Brasil

Arlindo Ribeiro Machado

Universidade de São Paulo, Brasil

César Geraldo Guimarães

Universidade Federal de Minas Gerais, Brasil

Cristiane Freitas Gutfreind

Pontifícia Universidade Católica do Rio Grande do Sul, Brasil

Denilson Lopes

Universidade Federal do Rio de Janeiro, Brasil

Eduardo Peñuela Cañizal

Universidade Paulista, Brasi

Erick Felinto de Oliveira

Universidade do Estado do Rio de Janeiro, Brasil

Francisco Menezes Martins

Universidade Tuiuti do Paraná, Brasil

Gelson Santana

Universidade Anhembi/Morumbi, Brasi

Hector Ospina

Universidad de Manizales, Colômbia

leda Tucherman

Universidade Federal do Rio de Janeiro, Brasil

Itania Maria Mota Gomes

Universidade Federal da Bahia, Brasil

Janice Caiafa

Universidade Federal do Rio de Janeiro, Brasil

Jeder Silveira Janotti Junior

Universidade Federal da Bahia, Brasil

\section{João Freire Filho}

Universidade Federal do Rio de Janeiro, Brasil

John DH Downing

University of Texas at Austin, Estados Unidos

José Luiz Aidar Prado

Pontifícia Universidade Católica de São Paulo, Brasil

José Luiz Warren Jardim Gomes Braga

Universidade do Vale do Rio dos Sinos, Brasil

Juremir Machado da Silva

Pontifícia Universidade Católica do Rio Grande do Sul, Brasil

Lorraine Leu

University of Bristol, Grã-Bretanha

Luiz Claudio Martino

Universidade de Brasília, Brasil

Maria Immacolata Vassallo de Lopes

Universidade de São Paulo, Brasil

Maria Lucia Santaella

Pontifícia Universidade Católica de São Paulo, Brasil

Mauro Pereira Porto

Tulane University, Estados Unidos

Muniz Sodre de Araujo Cabral

Universidade Federal do Rio de Janeiro, Brasil

Nilda Aparecida Jacks

Universidade Federal do Rio Grande do Sul, Brasil

Paulo Roberto Gibaldi Vaz

Universidade Federal do Rio de Janeiro, Brasil

Renato Cordeiro Gomes

Pontifícia Universidade Católica do Rio de Janeiro, Brasil

Ronaldo George Hela

Universidade do Estado do Rio de Janeiro, Brasil

Rosana de Lima Soares

Universidade de São Paulo, Brasil

Rossana Reguillo

Instituto Tecnológico y de Estudios Superiores do Occidente, México

Rousiley Celi Moreira Maia

Universidade Federal de Minas Gerais, Brasil

Sebastião Carlos de Morais Squirra

Universidade Metodista de São Paulo, Brasi

Simone Maria Andrade Pereira de Sá

Universidade Federal Fluminense, Brasil

Suzete Venturelli

Universidade de Brasília, Brasil

Valério Cruz Brittos

Universidade do Vale do Rio dos Sinos, Brasil

Veneza Mayora Ronsini

Universidade Federal de Santa Maria, Brasil

Vera Regina Veiga França

Universidade Federal de Minas Gerais, Brasil
COMISSÃO EDITORIAL

Ana Gruszynski I Universidade Federal do Rio Grande do Sul, Brasil

Rose Melo Rocha I Escola Superior de Propaganda e Marketing, Brasil

CONSULTORES AD HOC

Alberto Schneider I Visitante Tokyo University

Alexandre Rocha da Silva I Universidade Federal do Rio Grande do Sul, Brasil

Fernanda Bruno I Universidade Federal do Rio de Janeiro, Brasil

Ida Stumpf I Universidade Federal do Rio Grande do Sul, Brasil

Kati Caetano I Universidade Tuiuti do Paraná, Brasil

Laura Cánepa I Universidade Anhembi Morumbi, Brasi

Malena Contrera I Universidade Paulista, Brasil

Sandra Gonçalves I Universidade Federal do Rio Grande do Sul, Brasil

Vicente Gosciola I Universidade Anhembi Morumbi, Brasil

REVISÃO DE TEXTO E TRADUÇÃO I Everton Cardoso

EDITORAÇ̃̃o ELETRÔNICA I Raquel Castedo
COMPós I www.compos.org.br

Associação Nacional dos Programas de Pós-Graduação em Comunicação

Presidente

Erick Felinto de Oliveira

Universidade do Estado do Rio de Janeiro, Brasil erickfelinto@uol.com.br

Vice-presidente

Ana Silvia Lopes Davi Médola

Universidade Estadual Paulista, Brasil

asilvia@faac.unesp.br

Secretária-Geral

Denize Correa Araújo

Universidade Tuiuti do Paraná, Brasil

denizearaujo@hotmail.com 